\title{
The Clostridium perfringens Epsilon Toxin as a Bioterrorism Weapon
}

\section{Kapil Gaur ${ }^{1 *}$, Kshitija lyer ${ }^{2}$, Sumalatha Pola ${ }^{3}$, Richa Gupta ${ }^{4}$, Anil K Gadipelli ${ }^{5}$, Praveen Suddala ${ }^{6}$, Prakash Acharya ${ }^{7}$, Shounak Pal ${ }^{8}$ and Vishal Tripathy ${ }^{9}$}

${ }^{1}$ Deenbandhu Chhotu Ram University of Science and Technology, Murthal, Sonepat, Haryana 131039

${ }^{2}$ VIT University, Near Katpadi Road, Katpadi, Vellore, Tamil Nadu 632014

${ }^{3}$ Sathyabama University, Jeppiaar Nagar, Rajiv Gandhi Road, Solinganallur, Chennai, Tamil Nadu 600119

${ }^{4}$ IMS Engineering College, IMS Engineering College, Hapur Rd, Ghaziabad, Uttar Pradesh 201009

${ }^{5}$ Aurora research and Technological institute, JNTUH, Warangal, India

${ }^{6}$ Sri Krupa Institute of pharmaceutical Sciences, Siddipet, Andhra Pradesh, India

${ }^{7}$ Gandhi Institute of Technology and Management, Vishakapatnam

${ }^{8}$ SRM University, Guduvancheri, Tamil Nadu 603203

${ }^{9}$ Amity University, Sector 125, Noida, Uttar Pradesh 201313

\begin{abstract}
The Clostridium perfringens epsilon toxin made by the microorganism true bacteria could be a doubtless fatal bioterrorism weapon. If used effectively, this agent might cause important morbidity and mortality and, because of a scarcity of existing analysis into the result of this poison in humans, no therapeutic or preventive measures exist as medical countermeasures. Notable well for manufacturing severe medicine malady in domestic mammals, Clostridium perfringens epsilon toxin might be promptly weaponized and dispersed via AN orally ingestible or aerosol route. This critical review considers the present literature and tries to position stress on understanding this organism and this poison in its rightful place as AN agent of goodly concern to be used in act of terrorism attacks. The review includes a discussion of the bacteria genus, the precise toxins of $C$. perfringens in addition as focusing on Clostridium perfringens epsilon toxin above all.
\end{abstract}

Keywords: Clostridium; Bioterrorism; Toxin

\section{Introduction}

The genus Clostridium includes quite 100 species of gram positive anaerobic bacterium that live ubiquitously throughout the atmosphere, together with in traditional animal and human enteral flora $[1,2]$. Though the genus includes a mess of species, only a few cause serious un-healthiness together with true bacteria tetani, botulinum, and true bacteria difficult, that cause the clinical diseases tetanus, botulism, and $C$. difficile diarrhea infections respectively. Gas phlegmon is commonly a polymicrobial malady however is most ordinarily and significantly related to many true bacteria species, together with true bacteria sordelli, Clostridium novyi, true bacteria septicum and, most significantly, bio-arm.

Although the array of human diseases caused by this bacterium is wide, a vital characteristic that unites them in their mechanism is that the formation of powerful toxins that initiate the organic chemistry changes that turn out clinical disease [3]. In fact, the eubacteria and tetanus toxins are 2 of the foremost powerful and doubtless harmful substances glorious to science [4]. The exotoxin-producing characteristics of those bacterium are unit necessary in understanding not solely the clinical diseases that they turn out however additionally their methodology of getting and manufacturing energy. Several of the Clostridial species lack genes that code for the enzymes necessary for amino acid synthesis. Several of the toxins produces by Clostridia species, particularly those involved in myonecrotic conditions, degrade host tissue so as to reveal the bacterium to $\mathrm{AN}$ environment wherever these required substrates area unit on the market to be used in super molecule synthesis $[5,6]$. An understanding of the toxins made by every organism is important to understanding its un-wellness state likewise as potential medicine, medicine and preventive therapies. The characteristic toxin forming pathological process of this genus of bacterium is highlighted by the classification of its best-known poison, botulinum, as a class A (highest priority) agent of potential use in bioterrorism. The subsequent discussion can examine in bigger detail the Clostridium perfringens epsilon toxin of Clostridium perfringens, classified as class B by the CDC [7].

\section{The Organism}

Clostridium perfringens, like most different Clostridial species, is cosmopolitan within the environment in its reproductive structure type and is most typically found in soil, marine environments, and in the intestines of humans and variety of domesticated animals [8]. Its spores square measure metabolically inactive and square measure able to survive a good vary of environmental conditions, creating the bacterium very troublesome to kill in reproductive structure form [9]. Though information varies by experiment sort and race of spore, heat resistance of spores to inactivation at temperatures of between 90 $100^{\circ} \mathrm{C}$ has been observed [10]. This implies that the heartiest spores will actually survive a standard cooking method and it's conjointly been incontestable that by varied culture media and reactivation conditions, the warmth resistance is manipulated [11,12]. Clinical sickness needs germination of spores within the host tissue at which period the organism becomes metabolically active and begins to assert its morbific influence. The rugged and resilient nature of the C. perfringens reproductive structure create it simple to store and troublesome to eradicate and contributes to the priority that bacterium of this genus, as well because the eubacteria genus, can be used as terrorist

*Corresponding author: Kapil Gaur, B.tech Biotechnology, Deenbandhu Chhotu Ram University of Science and Technology, Murthal, Sonepat, Haryana 131039 Tel: 8376837633; E-mail: djgaur007@gmail.com

Received November 06, 2014; Accepted November 07, 2014; Published November 14, 2014

Citation: Gaur K, lyer K, Pola S, Gupta R, Gadipelli AK, et al. (2014) The Clostridium perfringens Epsilon Toxin as a Bioterrorism Weapon. J Microb Biochem Technol S8: 009. doi:10.4172/1948-5948.S8-009

Copyright: (c) 2014 Gaur K, et al. This is an open-access article distributed under the terms of the Creative Commons Attribution License, which permits unrestricted use, distribution, and reproduction in any medium, provided the original author and source are credited 
act weapons. However, in contrast to eubacteria anthracis that the reproductive structure type of the bacterium square measure the most viable means of dispersing the agent, $C$. perfringens may probably be weaponized victimization either its reproductive structure type or by purifying its toxins [13]. There are a minimum of 5 infective styles of $C$. perfringens, selected A, B, C, D, and E, each of that turn out their own profile of poisons. Though there are a unit over 10 projected specific toxins, those of primary concern area unit alpha, beta, epsilon, and iota in addition because the common but comparatively less dangerous C. perfringens cytotoxin. The foremost common human malady produced by $C$. perfringens is intestinal flu, caused by production of the $C$. perfringens enterotoxin within the gut. This syndrome has solely been definitively coupled to blood group perfringens and is sometimes a self-restricted, though uncomfortable, clinical syndrome [14]. The additional dangerous clinical entity in humans illustrious to be caused by C. perfringens is gangrenous sphacelus or emphysematous gangrene. Though emphysematous gangrene is sort of continually a poly microbial infection, $C$. perfringens is isolated from over eightieth of cases and is believed to be one of the foremost necessary species during this syndrome [15]. Conceptually, this syndrome is illustrative of the action of the toxins of $C$. perfringens in this it involves the secretion of poisons that disrupt the normal cellular design, inflicting leak of cellular contents that the bacterium uses to create energy and synthesize proteins. The alpha poisonous substance is believed to be the foremost necessary poisonous substance in the pathological process of this malady however the opposite poisonous substance varieties, particularly bacterial toxin will turn out specific malady states that are of interest [16]. Bacterial toxin is a crucial substance to understand and think about as a result of its illustrious association with veterinary malady and its potential to cause important health problem if distributed wide throughout a terrorist act attack.

\section{Microbiology of the Epsilon Toxin}

Epsilon toxin is made solely by $C$. perfringens varieties $\mathrm{B}$ and $\mathrm{D}$ and is secreted as a "protoxin" consisting of 311 amino acids that, once activated, produce the extremely potent active toxin. This activation consists of cleavage of a 14 -amino acid long phase from the $\mathrm{N}$-terminus of the protoxin by enzyme, a typical organic process catalyst found within the gut of humans and plenty of domesticated animals $[15,17]$. The poison Clostridium perfringens epsilon toxin bacterial toxin is expounded to the aerosol pore-forming toxin family and, upon activation, the poison undergoes a conformation modification, interacts with the cellular membrane and creates pores within the membrane that modification its porousness and quickly cytotoxic. In fact, the bacterial toxin is that the third most fatal among the clostridial toxins after true bacteria and tetanus toxins. The poison produces a water stuffed channel within the lipoid bilayer without sterilization the animate thing design of the cell. During this approach the poison works basically by "punching holes" in cell layers resulting in bigger porousness and edema $[5,18,19]$. The poison is the most stable at temperature for up to every week and far longer at colder temperatures [20].

\section{Naturally Occurring Clinical Disease}

The mechanism of action of this poisonous substance is very important in understanding the foremost common manifestation of unwellness caused by Clostridium perfringens epsilon toxin in animals, the customarily fatal "over-eating" or "pulp-kidney" unwellness ascertained in sheep, goats and kine. This unwellness may be a sort of enterotoxemia within which the micro-organism, specifically
C. perfringens kind D germinates within the gut. The likelihood of progression to death is dose dependent and depends upon the number of eaten toxin. An explicit unwholesomeness rate is troublesome to see through natural exposure as a result of the typical sort of the animal disease happens once Associate in Nursing animal ingests an oversized quantity of contaminated food and this food passes undigested into the intestines wherever poisonous substance production will increase. Thus, the chance of a fatal case is basically determined but the quantity of microorganism eaten by the animal [15]. However, the $\mathrm{LD}_{50}$ in mice once delivered intravenously is simply $0.1 \mu \mathrm{g} / \mathrm{kg}$ creating it a very potent agent [20]. The Clostridium perfringens epsilon toxin, once activated, causes exaggerated porosity of the lining of the gut and vascular epithelium, so permitting the poisonous substance to enter the circulation and ultimately resulting in hematongeous unfold of the poisonous substance to alternative finish organs as well as, most notably, the kidneys and brain. The poisonous substance will increase vascular porosity, its primary pathologic action resulting in lump and necrosis [21]. Several of the vital clinical symptoms are caused by edema of the brain and embrace opisthotonis, convulsions, and seizure; though fast death without clinically evident symptoms is additionally oft observed [22]. It's speculated that direct action of the poisonous substance on the hippocampus leading to unleash of salt is also chargeable for these symptoms $[18,23,24]$. In fact, the neurological symptoms is also mediate by direct impact of glutamate unleash additionally to the cerebral lump noted in these animals at autopsy [25].

\section{Epsilon Toxin as a Potential Bioterror Weapon}

Although the present sort of this malady happen once production and activation of bacterial toxin within the class gut, it's conjointly potential to visualize AN aerosolized form of the poisonous substance that can be used as a bioterrorist weapon. The severe medicine malady caused in alternative mammals combined with the high morbidness of the poisonous substance and also the relative dearth of research into the result of this substance on humans create it a sexy target for those that might alter it. As a bio-arm, bacterial toxin in its active type or in its protoxin type can be dispersed in food supposed for human consumption and, in high enough doses might probably cause animal disease kind of like that seen in sheep. The dose for this route of exposure isn't acknowledged for humans. In fact, even in animals, malady is caused by in vivo production of poisonous substance instead of bodily process of the poisonous substance itself, therefore it's unclear what dose of the poisonous substance would need to be eaten to cause clinical malady. Malady caused by $C$. perfringens eaten in the reproductive structure type by humans usually has a period of six to twenty four hours; but, symptom onset may be quicker if refined poisonous substance was ingested [26]. Another potential permutation of use as a bio-arm would be the inclusion of the terribly hearty and warmth stable spores as part of weapons that utilize shell so secondarily press on to own higher incidence of gas gangrene infections [27]. As with most potential act of terrorism weapons, the foremost feared and maybe most destructive technique of dispersing this poisonous substance would be through aerosolization. Only if this is often not the natural approach of coming back up-to-date with the poisonous substance and, obviously, no human studies have been conducted with relevancy this route of exposure, it's conjointly unclear what dose of the poisonous substance inhaled would be needed to cause malady. It's potential that the protoxin type can be aerosolized only if additionally to its presence within the gut, enzyme is created by immune cells in humans and is gift in human respiratory organ tissue. In fact, respiratory disorder caused by alpha-1antitrypsin deficiency results from destruction of respiratory 
organ tissue by this protein, once secreted by immune cells within the lung [28]. Additionally to the presence of this protein within the respiratory organ, a spread of other enzymes with enzyme like activity, as well as Human airway trypsin-like proteolytic enzyme area unit present in healthy human respiratory organ tissue [29]. The power of those alternative enzymes to activate letter of the alphabet pro-toxin isn't well elucidated. Though speculative, this means that it's going to be potential to generate malady in humans via aerosolization of either the poisonous substance which might be primarily active or the pro-toxin which ought to endure activation within the victim's respiratory organ tissue. While dispersion within the pro-toxin type would definitely be potential and possibly effective, the method of manufacturing active poisonous substance from protoxin has been well understood since at least the Nineteen Sixties and may be accomplished with relative ease victimization-commercially out there isolates of trypsin [30]. The potential to be used of this poisonous substance as a weapon is well completed and it absolutely was, in fact, found to have been created by the govt. of Asian country within the Eighties and 1990s [31]. In fact, over 3,400 liters of $C$. perfringens spores were believed to own been created by the Iraqi regime [32]. Although no acknowledged uses of the poisonous substance in AN actual attack area unit acknowledged, it actually has the potential to cause severe pneumonic and medicine malady if effectively weaponized.

\section{Vaccine and Treatment}

Toxoid vaccines area unit used normally in industrial cultivation, area unit well studied during a variety of animals, and area unit commercially accessible for sheep and goats $[33,34]$. These vaccines, while effective, confer varied degrees of medicine protection and area unit related to occasional inflammatory reactions and area unit typically not felt to be applicable to be used in humans [27]. Thus far comparatively very little progress has been created toward the assembly of a good human immunogen against $C$. perfringens or any type of anti-toxin and within the event of a terrorist attack, no prophylactic measures would possible be accessible to be used by the general public. However, in at least one murine model, sublimate mutated bacterial toxin immunogen did give protection in insusceptible mice. Associate application like this would possibly realize use in human medical specialty. Treatment of intoxication would be for the most part auxiliary. Little or no is thought regarding however clostridial toxin induced neurologic illness would manifest in humans then recognition and ulterior epidemiological investigation of this agent could prove troublesome.

\section{Discussion}

The bacterial toxin of eubacteria prefringens could be a probably dangerous terrorist act weapon. Intoxication through oral body process in animals of the microorganism in reproductive structure type produces severe and infrequently fatal sickness related to cerebral and different organ puffiness and a chop-chop fatal clinical syndrome. If effectively weaponized via associate degree aerosol or oral body process route, the toxic and deadly doses in humans don't seem to be farfamed. No human immunizing agent or specific therapeutic is available for treatment of bacterial toxin created sickness in humans, creating it all the additional attractive as a possible weapon of mass morbidity and mortality. Continued analysis and understanding of this agent are necessary to confirm protection against this agent.

\section{References}

1. Wells C, Wilkins T (1996) Clostridia: Spore-forming Anaerobic Bacilli. In:
Medical Microbiology, Baron S (4th edn), University of Texas Medical Branch at Galveston, USA.

2. Collins M (1994) The phylogeny of the genus Clostridium: proposal of five new genera and eleven new species combinations. Int J Syst Bacteriol 44: 812-826.

3. Identification of Clostridium Species. Issue no: 3 Issue date: 14.07 .08 Issued by: Standards Unit, Evaluations and Standards Laboratory.

4. Greenfield RA, Brown BR, Hutchins JB, landolo JJ, Jackson R, et al. (2002) Microbiological, biological, and chemical weapons of warfare and terrorism. Am J Med Sci 323: 326-340.

5. Popoff M, Bouvet P (2009) Clostridial toxins. Future Microbiol 4: 1021-1064.

6. Shimizu T, Ohtani K, Hirakawa H, Ohshima K, Yamashita A, et al. (2002) Complete genome sequence of Clostridium perfringens, an anaerobic flesheater. Proc Natl Acad Sci USA 99: 996-1001.

7. Schmaljohn C (2009) Vaccines for hantaviruses. Vaccine 27 Suppl 4: D61-64.

8. Matches JR, Liston J, Curran D (1974) Clostridium perfringens in the environment. Appl Microbiol 28: 655-660.

9. Paredes-Sabja D, Torres JA, Setlow P, Sarker MR (2008) Clostridium perfringens spore germination: characterization of germinants and their receptors. J Bacteriol 190: 1190-1201.

10. Adams DM (1973) Inactivation of Clostridium perfringens type A spores at ultrahigh temperatures. Appl Microbiol 26: 282-287.

11. Orsburn B, Melville SB, Popham DL (2008) Factors contributing to heat resistance of Clostridium perfringens endospores. Appl Environ Microbiol 74 3328-3335.

12. Ando $Y$, Tsuzuki T (1983) Mechanism of chemical manipulation of the heat resistance of Clostridium perfringens spores. J Appl Bacteriol 54: 197-202.

13. The Centers for Disease Control and Prevention. Emergency Preparedness and Response-Anthrax.

14. Joseph R. Lentino (2009) Merk Manuals, Clostridium perfringens Food.

15. McDonel JL (1980) Clostridium perfringens toxins (type A, B, C, D, E) Pharmacol Ther 10: 617-655

16. Sakurai J, Nagahama M, Oda M (2004) Clostridium perfringens alpha-toxin characterization and mode of action. J Biochem 136: 569-574.

17. The Center for Food Security and Public Health (2004) Epsilon Toxin of Clostridium perfringens, lowa State University.

18. Uzal FA, Vidal JE, McClane BA, Gurjar AA (2010) Clostridium perfringens Toxins Involved in Mammalian Veterinary Diseases. Open Toxinology J 2: 24-42.

19. Payne D (1997) The Clostridium perfringens epsilon toxin. Reviews in Medical Microbiology .Pp: S28-S30.

20. Hau J (2005) Handbook of Laboratory Animal Science, Van Hoosier G (2nd edn), CRC Press, USA. Pp: 36-37.

21. Smith LD (1979) Virulence factors of Clostridium perfringens. Rev Infect Dis 1: $254-262$.

22. Kusiluka L, Kambarage D (1996) Diseases Caused by Bacteria, Diseases of Small Ruminants A Handbook Common Diseases of Sheep and Goats in SubSaharan Africa.

23. Dorca-Arévalo J, Soler-Jover A, Gibert M, Popoff MR, Martín-Satué M, et al. (2008) Binding of epsilon-toxin from Clostridium perfringens in the nervous system. Vet Microbiol 131: 14-25.

24. Finnie JW, Blumbergs PC, Manavis J (1999) Neuronal damage produced in rat brains by Clostridium perfringens type $\mathrm{D}$ epsilon toxin. J Comp Pathol 120 415-420.

25. Miyamoto O, Minami J, Toyoshima T, Nakamura T, Masada T, et al. (1998) Neurotoxicity of Clostridium perfringens epsilon-toxin for the rat hippocampus via the glutamatergic system. Infect Immun 66: 2501-2508.

26. Illinois Department of Public Health. Clostridium perfringens.

27. Titball RW (2009) Clostridium perfringens vaccines. Vaccine 27 Suppl 4: D44-47.

28. Fauci A (1997) Part Nine, disorders of the respiratory system. In: Harrison's Principles of Internal Medicine (14th edn), Mcgraw-Hil, USA.1452-1453. 
Citation: Gaur K, Iyer K, Pola S, Gupta R, Gadipelli AK, et al. (2014) The Clostridium perfringens Epsilon Toxin as a Bioterrorism Weapon. J Microb Biochem Technol S8: 009. doi:10.4172/1948-5948.S8-009

Page 4 of 4

29. Matsushima R, Takahashi A, Nakaya Y, Maezawa H, Miki M, et al. (2006) Human airway trypsin-like protease stimulates human bronchial fibroblast proliferation in a protease-activated receptor-2-dependent pathway. Am J Physiol Lung Cell Mol Physiol 290: L385-395.

30. Orlans ES, Richards CB, Jones VE (1960) Clostridium welchii epsilon-toxin and antitoxin. Immunology 3: 28-44.

31. Cordesman A (1998) Iraqis Past and Future Biological Weapons Capabilities. CSIS Middle East Dynamic Net.
32. Davis CJ (1999) Nuclear blindness: An overview of the biological weapons programs of the former Soviet Union and Iraq. Emerg Infect Dis 5: 509-512.

33. de la Rosa C, Hogue DE, Thonney ML (1997) Vaccination schedules to raise antibody concentrations against epsilon-toxin of Clostridium perfringens in ewes and their triplet lambs. J Anim Sci 75: 2328-2334.

34. Uzal FA, Bodero DAV, Kelly WR, Nielsen K (1998) Variability of serum antibody responses of goat kids to a commercial Clostridium perfringens epsilon toxoid vaccine. Veterinary Record 143:472-474. 